ASTHMA

\title{
Time course of action of two inhaled corticosteroids, fluticasone propionate and budesonide
}

\author{
K Phillips, J Oborne, S Lewis, T W Harrison, A E Tattersfield
}

Thorax 2004;59:26-30. doi: 10.1136/thx.2003.015297

See end of article for authors' affiliations

.....................

Correspondence to: Dr K Phillips, Division of Respiratory Medicine Clinical Sciences Building, City Hospital, Nottingham NG5 1PB, UK: dr_kate_phillips@ hotmail.com

Received 26 August 2003 Accepted 2 October 2003
Background: It is important to be able to compare the efficacy and systemic effects of inhaled corticosteroids but their slow onset of action makes it difficult to measure the maximum response to a given dose. Submaximal responses could be compared if the time course of action of the inhaled corticosteroids being compared was similar. We have compared the time course of action of fluticasone and budesonide, measuring response as change in the provocative dose of adenosine monophosphate causing a $20 \%$ fall in forced expiratory volume in 1 second ( $\left.P D_{20} \mathrm{AMP}\right)$.

Methods: Eighteen subjects with mild asthma, aged 18-65, took part in a three way randomised crossover study. Subjects took fluticasone $(1500 \mu \mathrm{g} /$ day $)$, budesonide $(1600 \mu \mathrm{g} /$ day $)$, and placebo each for 4 weeks with a washout period of at least 2 weeks between treatments; $\mathrm{PD}_{20} \mathrm{AMP}$ and forced expiratory volume in 1 second $\left(\mathrm{FEV}_{1}\right)$ were measured during and after treatment. The time taken to achieve $50 \%$ of the maximum response (T50\%) was compared as a measure of onset of action.

Results: There was a progressive increase in $\mathrm{PD}_{20} \mathrm{AMP}$ during the 4 weeks of treatment with both fluticasone and budesonide but not placebo; the increase after 1 and 4 weeks was 2.28 and 4.50 doubling doses (DD) for fluticasone and 2.49 and 3.65 DD for budesonide. T50\% was 9.3 days for fluticasone and 7.5 days for budesonide with a median difference between fluticasone and budesonide of 0.1 days $(95 \% \mathrm{Cl}-1.4$ to 2.65$)$. There was a wide range of response to both inhaled corticosteroids but good correlation between the response to fluticasone and budesonide within subjects. $\mathrm{FEV}_{1}$ and morning peak expiratory flow rate (PEFR) increased during the first week of both active treatments and were stable thereafter. There was a small progressive improvement in nocturnal symptoms with both active treatments. Conclusion: $\mathrm{PD}_{20} \mathrm{AMP}$ was a more sensitive marker of response to inhaled corticosteroid therapy than $\mathrm{FEV}_{1}$ and PEFR. The time course of action of fluticasone and budesonide on $\mathrm{PD}_{20} \mathrm{AMP}$ is similar, suggesting that comparative studies of their efficacy using 1 or 2 week treatment periods are valid. When a new inhaled corticosteroid becomes available, a pilot study comparing its time course of action with that of an established corticosteroid should allow comparative studies to be performed more efficiently.
A lthough inhaled corticosteroids are very effective in asthma and well tolerated, their long term use may be associated with adverse effects. ${ }^{1-3}$ Inhaled corticosteroids have very different pharmacokinetic profiles ${ }^{4}$ and, since this is likely to affect their systemic activity relative to their therapeutic airway effects, ${ }^{5}$ it is important to be able to compare the airway and systemic effects of different inhaled corticosteroids.

The airway response to an inhaled corticosteroid increases gradually over several weeks ${ }^{67}$ and sometimes months, ${ }^{89}$ making it difficult to compare the maximum response to given doses of inhaled corticosteroids. Submaximal responses have been compared ${ }^{10-12}$ but this is only valid if the time course of effect of the different inhaled corticosteroids is similar. The optimum duration of studies designed to compare the efficacy of inhaled corticosteroids remains uncertain.

This study has been designed to determine the time course of onset and offset of action of fluticasone propionate and budesonide, two inhaled corticosteroids that are compared frequently and which have different pharmacokinetic profiles. ${ }^{45}$ Responsiveness was measured as change in the provocative dose of adenosine monophosphate causing a $20 \%$ fall in forced expiratory volume in 1 second $\left(\mathrm{PD}_{20} \mathrm{AMP}\right)$ since this was the most sensitive marker of the effects of an inhaled corticosteroid in our previous study, and it appears to be more sensitive than other measures of bronchial responsiveness. ${ }^{13-16}$

\section{METHODS}

\section{Subjects}

Subjects were included in the study if they were aged 18-65 years, had a diagnosis of asthma, symptoms consistent with asthma, and bronchial hyperresponsiveness to AMP ( $\mathrm{PD}_{20} \mathrm{AMP}$ less than $29.5 \mu \mathrm{M}$ at screening). Subjects were excluded if they had a forced expiratory volume in 1 second $\left(\mathrm{FEV}_{1}\right)$ of less than $60 \%$ predicted or if they were a current smoker or had a smoking history of more than 10 pack years. Those taking any asthma medication other than an inhaled short acting $\beta$ agonist as required or sodium cromoglycate were excluded as were those who had taken an inhaled steroid in the previous 4 weeks or oral steroids in the previous 3 months or had had an exacerbation or chest infection within 6 weeks. Women of child bearing age had to be using adequate contraception.

The study was approved by the Nottingham City Hospital research ethics committee and subjects gave written informed consent.

\section{Measurements}

$\mathrm{FEV}_{1}$ was measured by dry bellows spirometer (Vitalograph, Buckingham, UK) as the larger of two values within $100 \mathrm{ml}$. $\mathrm{PD}_{20} \mathrm{AMP}$ was determined using a breath activated dosimeter 


\begin{tabular}{|c|c|c|c|c|}
\hline Sex & Age & $\begin{array}{l}\text { Baseline FEV } 1 \\
\text { (\% predicted) }\end{array}$ & Reversibility $(\%) \dagger$ & $\mathrm{PD}_{20} \mathrm{AMP}(\mu \mathrm{M})$ \\
\hline M & 43 & 2.25 (73) & 36 & 0.23 \\
\hline M & 50 & $3.45(76)$ & 16 & 17.0 \\
\hline$M \ddagger$ & 46 & $2.8(79)$ & 14 & 6.4 \\
\hline $\mathrm{F}$ & 45 & $1.95(72)$ & 36 & 2.75 \\
\hline $\mathrm{F} \ddagger$ & 33 & $3.4(90)$ & 14 & 16.0 \\
\hline$M$ & 58 & $2.7(84)$ & 11 & 14.7 \\
\hline M & 40 & $2.55(60)$ & 28 & 0.12 \\
\hline M & 46 & 2.95 (91) & 13 & 23.0 \\
\hline M & 38 & $4.5(110)$ & 6 & 16.5 \\
\hline M & 36 & $4.45(95)$ & 13 & 2.25 \\
\hline $\mathrm{F} \ddagger$ & 44 & $2.35(71)$ & 9 & 3.20 \\
\hline$M$ & 42 & $1.95(60)$ & 17 & 1.10 \\
\hline M & 48 & 4.4 (116) & 12 & 14.7 \\
\hline M & 28 & $4.3(97)$ & 12 & 26.0 \\
\hline M & 38 & 3.75 (91) & 14 & 9.0 \\
\hline M & 63 & $2.95(90)$ & 8 & 2.70 \\
\hline M & 43 & $3.35(86)$ & 5 & 13.7 \\
\hline M & 35 & $2.3(60)$ & 19 & 0.56 \\
\hline Mean values & 43 & $3.1(83)$ & 16 & $4.48^{*}$ \\
\hline
\end{tabular}

(MEFAR, Brescia, Italy) set to nebulise for 1 second with a pause of 6 seconds at a pressure of $152 \mathrm{kPa}$. Adenosine monophosphate (Sigma, UK) was dissolved in $0.9 \%$ saline to give a doubling dose range from 0.115 to $472 \mu \mathrm{M}$. An initial inhalation of $0.9 \%$ saline was followed by doubling doses of AMP with $\mathrm{FEV}_{1}$ measured 2 minutes after each dose. The inhalation challenge was stopped once $\mathrm{FEV}_{1}$ had fallen by $20 \%$ from the post-saline value or the maximum dose of AMP had been inhaled. $\mathrm{PD}_{20}$ values were calculated by interpolation between the last two doses on the log dose-response scale; censored values above $472 \mu \mathrm{M}$ were arbitrarily assigned double the maximum dose $(944 \mu \mathrm{M})$ while a response to the initial saline inhalation was assigned the minimum dose $(0.115 \mu \mathrm{M})$. Subjects kept diary cards, recording peak flow rate as the highest of three attempts (mini-Wright peak flow meter), symptoms, and use of relief inhaler twice daily. All subjects received training in spirometric testing and AMP challenge before entry into the study.

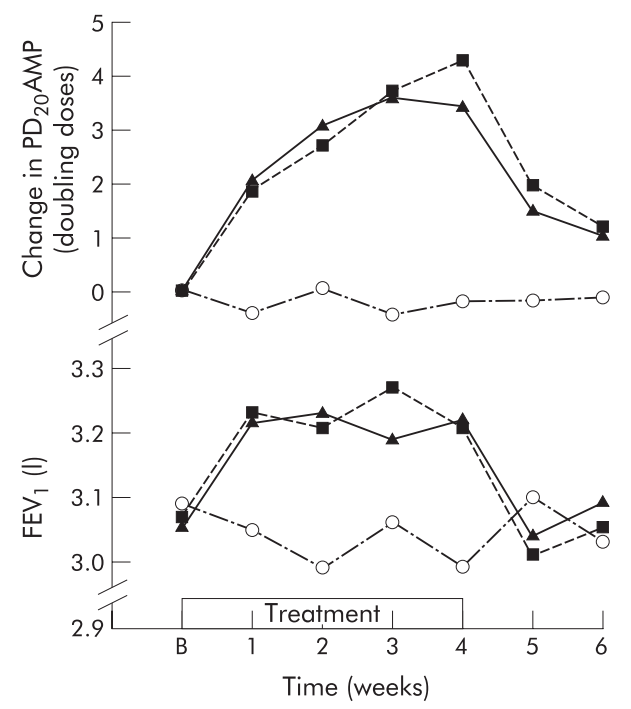

Figure 1 Change in mean $\mathrm{PD}_{20} \mathrm{AMP}$ (doubling doses) and $\mathrm{FEV}_{1}$ (I) during and after 4 weeks of treatment with fluticasone $1500 \mu \mathrm{g} /$ day and budesonide $1600 \mu \mathrm{g} /$ day. B, baseline; $\boldsymbol{\square}$, fluticasone; $\boldsymbol{\Lambda}$, budesonide; $\bigcirc$, placebo.

\section{Study protocol}

The study had a double blind, placebo controlled, crossover design with treatment order determined by an independent pharmacist using a computer generated random code. Treatment consisted of fluticasone $750 \mu \mathrm{g}$ twice daily by Accuhaler plus placebo by Turbohaler, budesonide $800 \mu \mathrm{g}$ twice daily by Turbohaler plus placebo by Accuhaler, or placebo by both Turbohaler and Accuhaler. At visit l subjects were taught to use the inhalers and were asked to take the treatment morning and evening 12 hours apart. There was a washout period of at least 14 days following each treatment period, extended if necessary until $\mathrm{PD}_{20} \mathrm{AMP}$ had returned to within two doubling doses of the baseline value.

Subjects attended weekly throughout the study, with all visits at the same time of day plus or minus 2 hours. Diary cards were checked and use of medication confirmed at each visit followed by spirometric testing and an AMP challenge. Subjects were asked to withhold their inhaled $\beta$ agonist for 6 hours before each visit and caffeine-containing food and drink from the previous midnight.

In the absence of prior data on individual time course of response, we chose to study 20 patients which would detect a difference in $\mathrm{PD}_{20} \mathrm{AMP}$ of one standard deviation.

\section{Analysis of data}

$\mathrm{PD}_{20}$ values were log transformed before analysis and geometric mean values calculated; change in $\mathrm{PD}_{20} \mathrm{AMP}$ was measured in doubling doses. The time taken to reach $50 \%$ of the maximum response over the 4 weeks (T50\%) was determined for each subject for each drug. Mean morning and evening PEFR and the percentage of days and nights free of symptoms and relief inhaler use were calculated for the 7 days before each visit. Two way analysis of variance (ANOVA) was used to look for period effects for change in $\mathrm{PD}_{20} \mathrm{AMP}$ and $\mathrm{FEV}_{1}$ and to compare treatment effects for change in $\mathrm{PD}_{20} \mathrm{AMP}, \mathrm{FEV}_{1}$, and PEFR after the first and last week of treatment and 1 and 2 weeks after stopping treatment. Paired $t$ tests with Bonferroni correction were used for post hoc pairwise comparisons between treatments. Within subject change in $\mathrm{PD}_{20} \mathrm{AMP}$ after fluticasone and budesonide was compared using Pearson's correlation coefficient and $\mathrm{T} 50 \%$ between active treatments by Wilcoxon's test. Symptom scores and relief inhaler use were compared using the Friedman test. 


\begin{tabular}{|c|c|c|c|c|}
\hline \multirow{2}{*}{$\begin{array}{l}\text { Week of } \\
\text { treatment }\end{array}$} & \multicolumn{3}{|c|}{ Mean $(95 \% \mathrm{Cl})$ change from baseline } & \multirow{2}{*}{$\begin{array}{l}\text { Mean }(95 \% \mathrm{Cl}) \text { difference } \\
\text { between fluticasone and } \\
\text { budesonide }\end{array}$} \\
\hline & Fluticasone & Budesonide & Placebo & \\
\hline 1 & $1.86(1.00$ to 2.72$)$ & 2.07 (1.42 to 2.72 ) & $-0.42(-0.94$ to 0.10$)$ & $-0.03(-0.77$ to 0.71$)$ \\
\hline 2 & $2.71(1.72$ to 3.70$)$ & 3.08 (2.04 to 4.12 ) & $0.04(-0.33$ to 0.41$)$ & $-0.37(-0.96$ to 0.22$)$ \\
\hline 3 & $3.71(2.68$ to 4.74$)$ & 3.61 (2.53 to 4.69$)$ & $-0.45(-1.06$ to 0.16$)$ & $0.10(-0.89$ to 1.09$)$ \\
\hline 4 & $4.30(3.12$ to 5.48$)$ & $3.45(2.12$ to 4.76$)$ & $-0.20(-0.97$ to 0.47$)$ & $0.38(-0.80$ to 1.52$)$ \\
\hline Washout 1 & $1.96(0.74$ to 3.18$)$ & 1.49 (0.34 to 2.64$)$ & $-0.20(-0.80$ to 0.40$)$ & 0.27 (-1.38 to 1.92$)$ \\
\hline Washout 2 & $1.18(0.19$ to 2.17$)$ & $1.03(0.18$ to 1.88$)$ & $-0.14(-0.95$ to 0.67$)$ & $0.06(-1.21$ to 1.33$)$ \\
\hline
\end{tabular}

\section{RESULTS}

Of 23 subjects randomised, five were excluded before unblinding the code, three due to non-compliance or withdrawal for personal reasons and two due to repeated failure to have a measurable $\mathrm{PD}_{20} \mathrm{AMP}$. Eighteen subjects completed the study although five missed one washout period due to worsening asthma (two subjects) or personal reasons (three subjects). Of 342 potential $\mathrm{PD}_{20} \mathrm{AMP}$ data points, all but 32 were available for analysis; 22 values were censored at $944 \mu \mathrm{M}$ but these were distributed evenly between the two active treatment groups (nine and eight during fluticasone and budesonide treatment plus five in the washout period).

The 18 subjects ( 15 men) included in the analysis had a mean age of 43 years. Baseline demographic data are shown in table 1. There was no period effect for change in $\mathrm{PD}_{20} \mathrm{AMP}$ or $\mathrm{FEV}_{1}$.

\section{Changes during and after treatment $\mathrm{PD}_{20} \mathrm{AMP}$}

There was a progressive increase in mean $\mathrm{PD}_{20} \mathrm{AMP}$ during treatment with fluticasone and budesonide but not placebo (fig 1, table 2). The difference in $\mathrm{PD}_{20} \mathrm{AMP}$ from placebo after 1 and 4 weeks of treatment was 2.49 and 3.65 doubling doses (DD) for budesonide and 2.28 and 4.50 DD for fluticasone. There was a difference between the three treatments after both $\mathrm{l}$ and 4 weeks $(\mathrm{p}<0.001)$ with budesonide and fluticasone differing from placebo (both $\mathrm{p}<0.001$ ) but not from each other. Median T50\% was 9.3 days for fluticasone

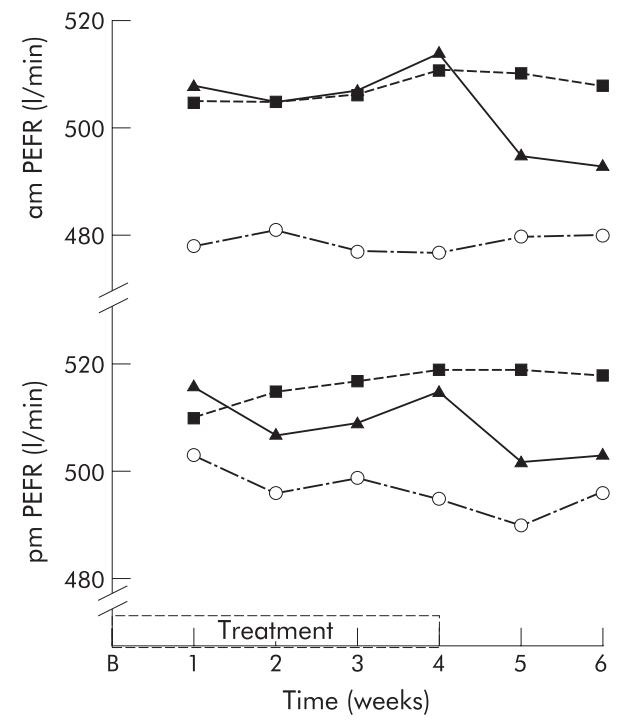

Figure 2 Mean morning and evening peak expiratory flow rate (PEFR, $\mathrm{I} / \mathrm{min}$ ) during and after 4 weeks of treatment with fluticasone $1500 \mu \mathrm{g} /$ day and budesonide $1600 \mu \mathrm{g} /$ day. B, baseline; $\mathbf{\square}$, fluticasone; $\boldsymbol{\Lambda}$, budesonide; $\bigcirc$, placebo. and 7.5 days for budesonide with a median difference between the two of 0.1 days ( $95 \%$ CI -1.4 to 2.65 ; p = 0.5).

Following cessation of treatment there was a progressive reduction in $\mathrm{PD}_{20} \mathrm{AMP}$ for both active drugs. After 1 week of washout there was no difference between active treatments although fluticasone but not budesonide differed from placebo $(p=0.03)$; after 2 weeks there was no difference between the three treatments.

\section{$\mathrm{FEV}_{1}$ and diary card data}

$\mathrm{FEV}_{1}$ increased by approximately $150 \mathrm{ml}$ during the first week with both active drugs but showed no further increase thereafter (fig 1). The differences between the three treatments were not significant at 1 week but after 4 weeks the difference was significant $(\mathrm{p}=0.01)$. $\mathrm{FEV}_{1}$ returned rapidly to baseline when treatment was stopped with no difference between treatments after 1 week.

Morning PEFR was approximately $30 \mathrm{ml}$ higher for each active treatment than for placebo after 1 week with no further increase thereafter $(\mathrm{p}<0.001$ after 1 and 4 weeks; fig 2). Evening PEFR was around $10 \mathrm{ml}$ higher than placebo with both active treatments and the difference was only significant at 4 weeks. Daytime symptoms did not change significantly whereas nocturnal symptoms fell with both fluticasone and budesonide; by 4 weeks the median percentage of nights free of symptoms was $100 \%$ with both active treatments compared with $63 \%$ for placebo $(p=0.001)$.

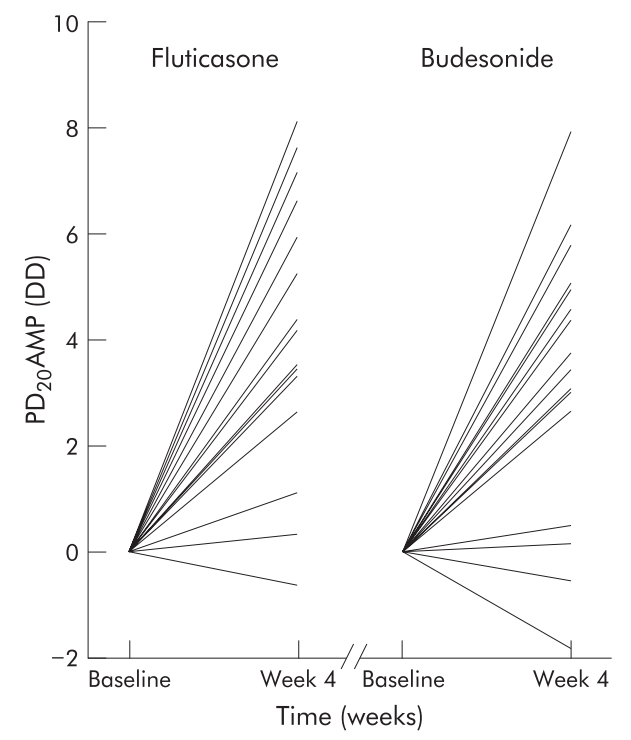

Figure 3 Individual changes in $\mathrm{PD}_{20} \mathrm{AMP}(\mathrm{DD})$ after 4 weeks of treatment with fluticasone $1500 \mu \mathrm{g} /$ day and budesonide $1600 \mu \mathrm{g} /$ day. 


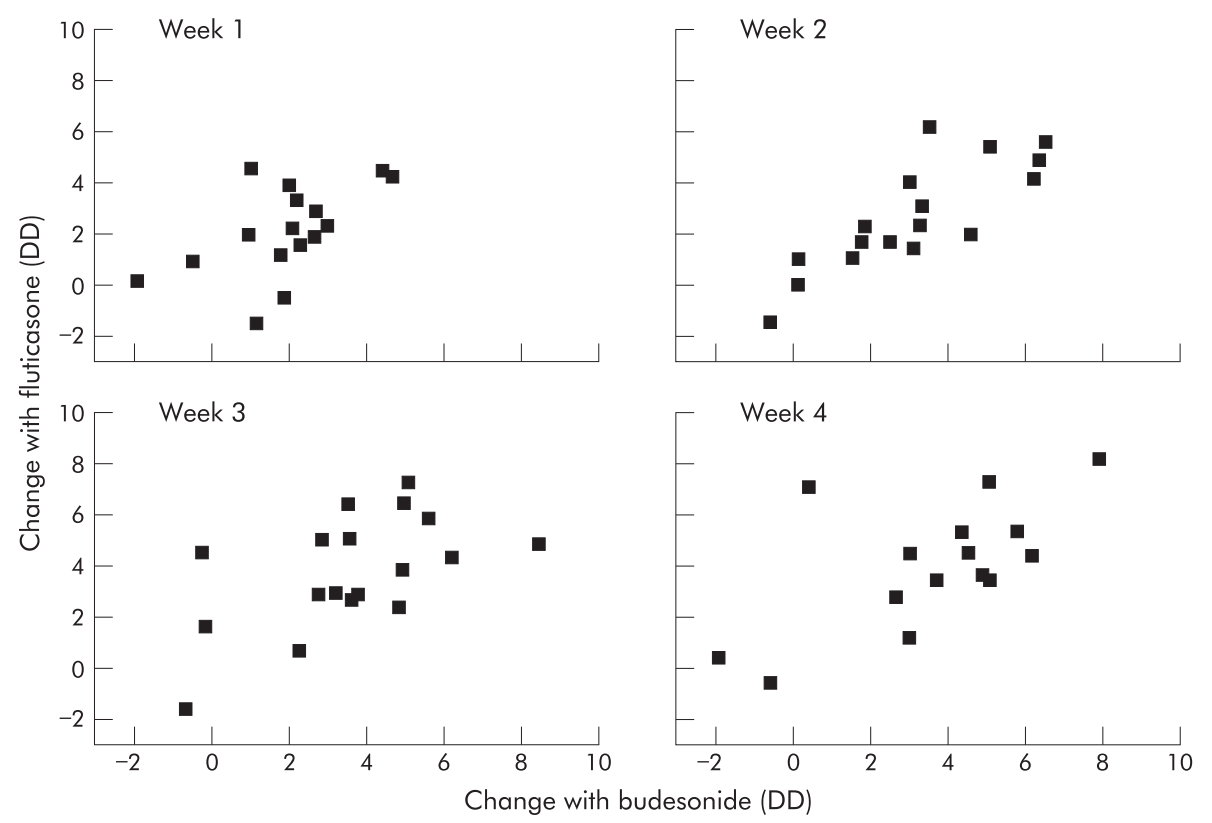

Figure 4 Individual changes in $\mathrm{PD}_{20} \mathrm{AMP}$ from baseline (doubling doses) after 1, 2, 3, and 4 weeks of treatment with fluticasone and budesonide. Pearson's correlation coefficient $=0.56,0.83,0.57$, and 0.61 for weeks $1,2,3$, and 4 .

\section{Individual variation in response}

There was a wide range of response to both inhaled corticosteroids between subjects, as shown in fig 3. After 4 weeks of treatment the change in $\mathrm{PD}_{20} \mathrm{AMP}$ from baseline ranged from -1.9 to $8.0 \mathrm{DD}$ for budesonide and from -0.6 to 8.1 DD for fluticasone. The change in $\mathrm{PD}_{20} \mathrm{AMP}$ for budesonide correlated significantly with the change in $\mathrm{PD}_{20} \mathrm{AMP}$ for fluticasone after each week of treatment (fig 4). Three subjects showed little response to budesonide and fluticasone (mean change in $\mathrm{PD}_{20} \mathrm{AMP}<0.9 \mathrm{DD}$ during both active treatments). These three subjects did not differ from the subject population in terms of demographic data (table 1) nor in their bronchodilator response to a $\beta$ agonist $(9 \%, 14 \%$, and $14 \%$ increase in $\mathrm{FEV}_{1}$ respectively).

\section{DISCUSSION}

In this three way crossover study in subjects with mild asthma there was a progressive increase in $\mathrm{PD}_{20} \mathrm{AMP}$ during 4 weeks of treatment with fluticasone and budesonide of the order of four doubling doses. The time course of change in $\mathrm{PD}_{20} \mathrm{AMP}$ was similar for fluticasone and budesonide. There was a small increase in $\mathrm{FEV}_{1}$ and morning PEFR after 1 week of treatment with both fluticasone and budesonide with no further increase thereafter. Individual responses to inhaled corticosteroid therapy varied considerably but within subjects the response to fluticasone and budesonide correlated closely.

Previous studies have shown that the response to an inhaled corticosteroid may continue to increase for weeks or even months after starting treatment. ${ }^{6-9}$ Using the maximum response to a given dose to compare efficacy is therefore impractical and some studies have used a submaximal response. ${ }^{10-12}$ However, this approach is only valid if the two drugs being compared have a similar onset of action. The aim of the present study was to determine the time course of action of fluticasone and budesonide. We chose doses of the drugs believed to be roughly equally effective when given via their respective dry powder inhalers. ${ }^{17-19}$

Bronchial responsiveness to adenosine monophosphate was selected as a proxy measure of clinical efficacy since our previous study showed it to be a more sensitive marker of response to an inhaled corticosteroid than $\mathrm{FEV}_{1}, \mathrm{PEFR}$, and symptoms. ${ }^{20}$ Change in $\mathrm{PD}_{20} \mathrm{AMP}$ also appears to be more sensitive than other measures of bronchial responsiveness, including methacholine, bradykinin and sodium metabisulphite. $^{13-16}$ Histamine and AMP have not been compared directly, but in a previous study $1600 \mu \mathrm{g}$ budesonide produced an increase in $\mathrm{PD}_{20}$ histamine of only $1.3 \mathrm{DD}$ over 3 weeks in patients with mild asthma. ${ }^{6}$ Change in $\mathrm{PD}_{20} \mathrm{AMP}$ has also been shown to correlate with more established markers of clinical efficacy following corticosteroid treatment in subjects with more severe asthma including $\mathrm{FEV}_{1}^{152122}$ and circadian variation in PEFR, ${ }^{15}$ as well as with markers of airway inflammation such as sputum eosinophils, eosinophil cationic protein, and exhaled nitric oxide. ${ }^{21} 22$

The increase in $\mathrm{PD}_{20} \mathrm{AMP}$ values seen after inhaled corticosteroid treatment led to some censored values which may have caused the mean change in $\mathrm{PD}_{20} \mathrm{AMP}$ with treatment to be underestimated. Since the number of censored values was small and distributed evenly between the two active treatment groups, this should not have affected the outcome materially. The increase in $\mathrm{PD}_{20} \mathrm{AMP}$ was large and the variability was small relative to the changes. Changes in $\mathrm{FEV}_{1}, \mathrm{PEFR}$, and symptoms were smaller, as in our previous study, ${ }^{20}$ strengthening support for $\mathrm{PD}_{20} \mathrm{AMP}$ as the outcome measure of choice for comparative studies of inhaled corticosteroids.

The progressive increase in $\mathrm{PD}_{20} \mathrm{AMP}$ during 4 weeks of treatment with fluticasone and budesonide was similar with no difference in the median time taken to achieve $50 \%$ of the maximum response. Following cessation of inhaled corticosteroid treatment there was no significant effect of treatment on $\mathrm{PD}_{20} \mathrm{AMP}$ after 2 weeks, as in our previous study with histamine. ${ }^{6}$ A few subjects had values of more than 2 DD above baseline values, however, and required a third week of washout according to the protocol ( 8 and 6 for fluticasone and budesonide, respectively), suggesting that washout periods should be at least 2 weeks and probably 3 weeks long.

This study also highlights the wide variation in the individual response to inhaled corticosteroids and the good within subject correlation for the effects of fluticasone and budesonide on bronchial responsiveness. This suggests that 
the repeatability of the test is good despite the occasional rogue value (fig 4). Three subjects showed little or no response to either inhaled corticosteroid over the 4 weeks. Including subjects with a poor response reduces the power of studies designed to compare inhaled corticosteroids and raises the question of whether screening would enable such subjects to be identified and omitted. A review of our results suggests that, had we excluded subjects in whom $\mathrm{PD}_{20} \mathrm{AMP}$ had changed by less than 1.5 DD after 2 weeks of either drug, we would have excluded the three subjects with a poor response plus one other subject.

We conclude that, because the time course of action of fluticasone and budesonide on $\mathrm{PD}_{20} \mathrm{AMP}$ is similar, studies comparing these drugs over 1-2 weeks are valid. For future crossover studies a treatment period of 1 or 2 weeks followed by a washout period of at least 2 weeks would seem reasonable. The inclusion of a 2 week screening period to identify subjects who respond to an inhaled corticosteroid should be considered. When new inhaled corticosteroids become available, a pilot study to compare their time course of action with that of an established corticosteroid should allow comparative studies to be performed more efficiently.

\section{ACKNOWLEDGEMENTS}

The authors thank AstraZeneca and GlaxoSmithKline for providing indistinguishable active and placebo inhalers, Sarah Pacey (Senior Pharmacist) for subject randomisation and dispensing the medication, and Sarah Newton and Sue Cooper for their help with subject visits.

\section{Authors' affiliations}

K Phillips, J Oborne, S Lewis, T W Harrison, A E Tattersfield, Division of Respiratory Medicine, University of Nottingham, City Hospital, Nottingham NG5 1PB, UK

\section{REFERENCES}

1 Cumming RG, Mitchell P, Leeder SR. Use of inhaled corticosteroids and the risk of cataracts. N Engl J Med 1997;337:8-14.

2 Garbe E, LeLorier J, Boivin JF, et al. Inhaled and nasal glucocorticoids and the risks of ocular hypertension or open angle glaucoma. JAMA 1997;277:722-7.

3 Wong CA, Walsh $\sqcup$, Smith CJP, et al. Inhaled corticosteroid use and bone mineral density in patients with asthma. Lancet 2000;355:1399-403.

4 Johnson M. Pharmacodynamics and pharmacokinetics of inhaled glucocorticoids. J Allergy Clin Immunol 1996:97:169-76.

5 Harrison TW. Systemic availability of inhaled budesonide and fluticasone propionate. Biodrugs 2001;15:405-11.
6 Vathenen AS, Knox AJ, Wisniewski A, et al. Timecourse of change in bronchial reactivity with an inhaled corticosteroid in asthma. Am Rev Respir Dis 1991; 143:1317-21

7 Kraan J, Koëter GH, Van Der Mark ThW, et al. Dosage and time effects of inhaled budesonide on bronchial hyperreactivity. Am Rev Respir Dis 1988; 137:44-8.

8 Haahtela T, Järvinen $M$, Kava T. Comparison of a $\beta_{2}$-agonist, terbutaline, with an inhaled corticosteroid, budesonide, in newly detected asthma. NEngl J Med $1991 ; 325: 388-92$

9 Juniper EF, Kline PA, Vanzieleghem MA, et al. Effect of long term treatment with an inhaled corticosteroid (budesonide) on airway hyperresponsiveness and clinical asthma in nonsteroid-dependent asthmatics. Am Rev Respir Dis 1990;142:832-6.

10 Nielsen LP, Dahl R. Therapeutic ratio of inhaled corticosteroids in adult asthma. A dose-range comparison between fluticasone propionate and budesonide, measuring their effect on bronchial hyperresponsiveness and adrenal cortex function. Am J Respir Crit Care Med 2000; 162:2053-7.

11 Bootsma GP, Dekhuijzen PN, Festen J, et al. Comparison of fluticasone propionate and beclomethasone dipropionate on direct and indirect measurements of bronchial hyperresponsiveness in patients with stable asthma. Thorax 1995;50:1044-50.

12 Jenkins CR, Woolcock AJ. Effect of prednisolone and beclomethasone dipropionate on airway responsiveness in asthma: a comparative study. Thorax 1988;43:378-84.

13 O'Connor BJ, Ridge SM, Barnes PJ, et al. Greater effect of inhaled budesonide on adenosine $5^{\prime}$-monophosphate induced than on sodium metabisulphite induced bronchoconstriction in asthma. Am Rev Respir Dis 1992;146:560-4.

14 Weersink EJM, Douma RR, Postma DS, et al. Fluticasone propionate, salmeterol xinafoate and their combination in the treatment of nocturnal asthma. Am J Respir Crit Care Med 1997;155:1241-6.

15 Meijer RJ, Kerstiens HAM, Arends LR, et al. Effects of inhaled fluticasone and oral prednisolone on clinical and inflammatory parameters in patients with asthma. Thorax 1999;54:894-9.

16 Doull IJ, Sandall D, Smith S, et al. Differential inhibitory effect of regular inhaled corticosteroid on responsiveness to adenosine-5' ${ }^{\prime}$-monophosphate, methacholine and bradykinin in symptomatic children with recurrent wheeze. Paediatr Pulmonol 1997;23:404-11.

17 Hindle M, Duncan AG, Newton MD, et al. Dry powder inhalers are bioequivalent to metered-dose inhalers. Chest 1995;107:629-33.

18 Pieters WR, Stallaert RA, Prins J, et al. A study on the clinical equivalence and patient preference of fluticasone propionate $250 \mu \mathrm{g}$ twice daily via the Diskus/Accuhaler inhaler and the Diskhaler in adult asthmatic patients. J Asthma 1998;35:337-45.

19 Thorsson L, Edsbäcker S, Conradson T-B. Lung deposition of budesonide from Turbuhaler is twice that from a pressurized metered-dose inhaler P-MDI. Eur Respir J 1994;7:1839-44.

20 Phillips K, Oborne J, Harrison TW, et al. Use of sequential quadrupling dose regimens to study efficacy of inhaled corticosteroids in asthma. Thorax 2004;59:21-5

21 Van Den Berge M, Kerstjens HAM, Meijer RJ, et al. Corticosteroid-induced improvement in the $\mathrm{PC}_{20}$ of adenosine monophosphate is more closely associated with reduction in airway inflammation than improvement in the $\mathrm{PC}_{20}$ of methacholine. Am J Respir Crit Care Med 2001;164:1 127-32.

22 Van Velzen E, Van Den Bos J-W, Benckhuijsen JAW, et al. Effect of allergen avoidance at high altitude on direct and indirect bronchial hyperresponsiveness and markers of inflammation in children. Thorax $1996 ; 51: 582-4$ 